\title{
Covid-19 Treatment: A Narrative Review of the Research and Evidence Thus Far
}

\author{
SM Zubair Rahim MBBS BSc (Hons) MRCP, Derek L Connolly BSc (Hons) MB ChB (Edin) PhD \\ (Cantab) FRCP, Arvind B Rajasekaran MBBS FRCP and Vinoda Sharma MBBS FRCP*
}

Sandwell \& West Birmingham Hospitals NHS Trust, United Kingdom

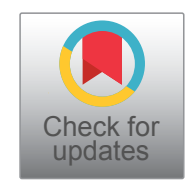

\begin{abstract}
The emergence of the novel SARS-CoV-2 virus has led to an unprecedented global pandemic with a high degree of morbidity and mortality. Treatment regimens around the world have been varied both in their drug combinations and the levels of evidence behind them. Drugs that have been used for other immune modulating purposes are being retrialled to try to combat this disease, with data showing far from conclusive results. We will examine the most common treatment strategies, including the rationale and evidence behind their use. Our conclusion, which is becoming universally realised amongst researchers, is that much more evidence is required to prove clinical efficacy of many of the currently available treatments.
\end{abstract}

\begin{abstract}
Abbreviations
TTR: Time to Recovery; HR: Hazard Ratio; RR: Risk Ratio; Cl: Confidence Interval; RCT: Randomised Controlled Trial; ARDS: Acute Respiratory Distress Syndrome; LMWH: Low Molecular Weight Heparin; HFNO: High Flow Nasal Oxygen; CPAP: Continuous Positive Airway Pressure; MHRA: Medicines \& Health Regulatory Agency; FDA: Food \& Drug Administration
\end{abstract}

\section{Introduction}

2020 will go down in history as the year that revealed much about our progress, or perhaps lack thereof, in so many aspects of science, society and culture. Covid-19 has affected every corner of the world. It all began with reports of a new viral illness infecting the residents of Wuhan, the capital city of China's Hubei province. The virus was formally identified in December 2019 as a variant of coronavirus, the family of viruses that had previously caused the outbreaks known as SARS (Severe Acute Respiratory Syndrome) in 2003 and MERS (Middle East Respiratory Syndrome) in 2012, and it was then given the official name SARS-CoV-2 [1].

As of $9^{\text {th }}$ December 2020, there have been over 67.2 million confirmed cases worldwide with over 1.5 million deaths [2]. However, the true number of infections is estimated to be between 3 and 20 times higher, due to incomplete testing of populations as well as false negative rates [3]. The disease resulting from the virus, now called Covid-19 (a contraction of Coronavirus disease 2019), presents with a spectrum of symptoms ranging from asymptomatic or mild malaise to the most severe symptoms of respiratory failure with acute respiratory distress syndrome. The most common presentation is recognised as the combination of fever, non-productive cough and breathlessness, with anosmia also being relatively common and diarrhoea more rare [4]. Of the diagnosed cases worldwide, around $20 \%$ require additional respiratory support, with a similar proportion of these requiring ventilation due to severe acute respiratory distress syndrome (ARDS) [5].

Detection methods include Reverse Transcription Polymerase Chain Reaction (RT-PCR) analysis of oropharyngeal aspirate samples, Computed Tomography (CT) imaging of the chest, blood cell differential count and biochemical parameters (such as lymphopenia) and the combination of clinical features with exposure to infected individuals [4].

Treatment options are largely supportive, including the management of fever, hypoxia and dehydration, according to standard healthcare methods. The disease is thought to have two phases; an initial phase of incubation, prodromal illness and emergence of the symptoms as described in the first week, which is followed in some cases by a hyper-immune response in the second week, which can lead to respiratory failure, multi-organ failure and death [5].

While research into the discovery and development of

*Corresponding author: Dr Vinoda Sharma, Consultant Interventional Cardiologist Sandwell \& City Hospitals NHS Trust Birmingham B18 7QH, United Kingdom, Tel: +44121 5075841

Accepted: December 28, 2020

Published online: December 30, 2020

Citation: Rahim SMZ, Connolly DL, Rajasekaran AB, et al. (2020)

Covid-19 Treatment: A Narrative Review of the Research and Evidence Thus Far. Sch J Emerg Med Crit Care 4(1):96-105 
a vaccine began almost immediately, the reality was that the process of taking a novel treatment from lab to bedside would require at least a year, not least of all to ensure sufficient long term safety data. Researchers therefore turned their attention to pre-existing, already approved agents for antiviral and immune modulatory purposes, with many drugs being repurposed under the pretexts of off-label or emergency use authorisations, the most popular of which we shall explore below.

\section{Drugs with Antiviral Activity}

\section{Chloroquine, Hydroxychloroquine, Azithromycin \& Ivermectin}

Chloroquine is a famous antimalarial drug of the quinolone class, discovered almost a century ago. It has been observed to have antimalarial, anti-inflammatory and immune modulatory functions, and along with its safer derivative hydroxychloroquine, it has become ubiquitously used in the treatment of connective tissue and autoimmune diseases [6]. The mechanism of action is purported to be through a combination of alkalinisation of endosomal $\mathrm{pH}$, preventing binding of foreign agents, as well as preventing glycosylation of Angiotensin Converting Enzyme II (ACE-II), which in turn inhibits the ability of virus particles to gain entry into the host cell [6].

Azithromycin is an antibiotic of the macrolide class, commonly used in the treatment of Gram-positive as well as atypical bacterial infections. It has also been demonstrated to have anti-inflammatory and immune-regulatory properties in vitro as well as in clinical studies, particularly with respiratory viral infections such as influenza [7].

Prior to its attempted use to treat Covid-19, Chloroquine had shown promising in vitro results but failed to show efficacy in both animal and clinical trials when tested against the previous coronaviruses (SARS-CoV $[6,8]$ and MERS-CoV), as well as against HIV (Human Immunodeficiency Virus) and even the Influenza virus [9].

Early on in the emergence of Covid-19, Chinese investigators once again demonstrated the in vitro potential of Chloroquine for preventing virus to cell entry, as well as mitigating the infectious effects post-entry [10]. An initial clinical trial with 100 patients in Wuhan suggested reduction in the duration and severity of symptoms and improvement in radiographic findings, although this study was not fully published for peer review [11].

Similar non randomised open label trials were conducted in France, including regimens of hydroxychloroquine in combination with Azithromycin, which were primarily designed to prove safety $[12,13]$. The largest observational study ( $n=$ 1438) comparing the use of hydroxychloroquine alone, or in combination with Azithromycin, showed no statistically significant difference in mortality compared to Covid-19 patients hospitalised in New York receiving the usual standard of care [14].

Randomised controlled trials (RCTs) have similarly failed to show benefit of hydroxychloroquine in both hospitalised confirmed cases, as well as for post-exposure prophylaxis purposes in non-hospitalised patients exposed to Covid-19 [15-18]. This includes the UK based Randomised Evaluation of COVid-19 thERapY (RECOVERY) collaborative group trial, which ran until June 2020, showing no difference in 28 day mortality for hospitalised patients and in fact suggesting increased risk of progress to invasive ventilation or death [18].

Safety concerns have also been raised over the use of hydroxychloroquine with or without azithromycin, particularly cardio-toxic and pro-arrhythmic effects purportedly driven by QT prolongation, which had already been observed prior to the use of these drugs in Covid-19 treatment [19]. In a randomised controlled trial including 504 confirmed Covid-19 patients, the frequency of QT prolongation and liver enzyme derangement was increased in those given hydroxychloroquine alone, as well as in combination with azithromycin [17]. Systematic review of trials has found between 10 and $23 \%$ incidence of QT prolongation, with a higher frequency of QT prolongation $>500 \mathrm{~ms}$ in those treated with the combination of two drugs, including reports of associated ventricular arrhythmias requiring emergency cardioversion [20].

Multiple meta-analyses have now been published, which confirm increased risk of adverse effects and no mortality benefit with the use of hydroxychloroquine for Covid-19 treatment $[21,22]$ and instead a significant increase in mortality when combined with azithromycin [22].

In conclusion, the evidence for the efficacy of hydroxychloroquine alone or in combination is unsubstantiated and in fact may confer additional risk to Covid-19 patients. It is currently widely recommended that all patients enrolling on a trial including hydroxychloroquine should have their $\mathrm{QT}_{c}$ interval monitored during treatment, and prior consideration of the risk to benefit profile should be taken for those at increased risk of cardio-toxic effects [23].

Ivermectin is a drug licensed as an anti-parasitic medication, which has also been observed to have antibacterial, antiviral and anti-neoplastic effects [24,25]. In vitro studies showed its effectiveness in inhibition of SARS-CoV-2 [26], signalling its potential as a treatment. Pilot observational studies have been promising both for mortality benefit and symptom improvement $[27,28]$, and several RCTs are underway to evaluate this further.

\section{The antiviral agents: Remdesivir, Favipiravir, Lopinavir/Ritonavir \& Interferon Beta-1a}

Several antiviral agents, all already in existence at the start of the Coronavirus pandemic, have been trialled in an attempt to show efficacy in combating Covid-19.

Remdesivir has probably received the most press due to its patenting and promotion by the American pharmaceutical company Gilead Sciences. It is a broad spectrum antiviral, which has consistently shown efficacy both in in vitro and animal models, demonstrating inhibition of SARS-CoV-1 and MERS-CoV [29]. It is an adenosine analogue that is metabolised intracellularly to an analogue of Adenosine Tri-phosphate (ATP), which then serves to compete with natural ATP in the RNA polymerase chain reaction, thereby interrupting 
viral replication $[29,30]$.

Remdesivir had been considered as a potential antiviral treatment for Ebola virus, which caused its own transcontinental pandemic in 2018 and 2019. However, it failed to demonstrate significant positive outcomes in the PALM (Pamoja Tulinde Miasha) trial, an RCT involving 681 Ebola patients; in fact it actually showed a significantly worse mortality rate compared to the antibody treatment arm [31].

Once again, Remdesivir showed promise in vitro and in animal models for effective SARS-CoV-2 inhibition [10,32], and RCTs got underway. The first of these, conducted by Chinese investigators, found no significant difference versus placebo in Time to Recovery (TTR), viral load or mortality $(n=$ 236) [33].

In April 2020, two sets of trial results were announced. The Adaptive COVID-19 Treatment trial (ACTT) which enrolled 1062 patients across multiple international centres (US, Europe and Asia), showed a 31\% improvement in median recovery time compared to placebo (10 days versus 15 days, $\mathrm{p}<$ 0.001 ). However, no significant mortality benefit was found [34]. The manufacturer of Remdesivir, Gilead Sciences announced the results of their funded RCT, the SIMPLE trial, purporting to show no added safety concerns from the use of 5 day or 10 day courses of Remdesivir in addition to the standard of care $(n=397)$. However, no significant difference in TTR or mortality was found between the two treatment course lengths, although the frequency of side effects in the 5 day course arm was reduced. This study was limited by the absence of a placebo control arm [35]. Nonetheless Remdesivir (now under the trade name Veklury), as of $22^{\text {nd }}$ October 2020, has gained full approval in the US to treat Covid-19 [36].

Similarly, the antivirals Favipiravir, Lopinavir and Ritonavir used both individually and in combination also showed initial promise with case reports of success in treating Covid-19 [37]. Lopinavir and Ritonavir is a well- known combination for anti-retroviral treatment in HIV, and had previously been used in the SARS outbreak of 2003 [38]. Multiple small RCTs were conducted, the largest of which $(n=199)$ showed no statistically significant benefit in mortality, viral load or TTR. It is to be noted however, that this was a cohort of patients with severe Covid-19 symptoms requiring supplemental oxygenation [39]. The UK's RECOVERY group also found a negative result in patients randomised to the Lopinavir/Ritonavir combination versus usual standard of care, with no significant difference in 28 day mortality, median time to discharge from hospital, and no difference in proportion progressing to mechanical ventilation [40].

Most damning of all was the recent publication of the World Health Organisation's SOLIDARITY study on $15^{\text {th }}$ October 2020. This was an open-label international trial investigating Remdesivir, Hydroxychloroquine, Lopinavir/Ritonavir and Interferon-beta 1a, as four separate treatment arms versus placebo controls. It involved the randomisation of 11266 hospitalised patients (2750 of which were randomised to Remdesivir) in 405 hospitals across 30 countries. No statistically significant benefit for mortality, TTR or severity of illness was found with any of these treatments [41]. Gilead sciences claimed a lack of robustness in the WHO data and analysis, which is interesting given the large numbers of patients involved, although they argued that this would increase the confounding factors from variable inclusion criteria, varying international standards of care and severity of illness of the participants [42].

Like the other agents investigated in the WHO SOLIDARITY study, Interferon-beta 1a was repurposed from its licensed indications for viral hepatitis and for multiple sclerosis. It is a recombinant human Type I interferon (naturally occurring signalling proteins known to be part of the innate antiviral immune response) and showed in vitro promise at clearing viral loads by inhibiting viral replication [43]. Multiple trials are ongoing, but the WHO data included 1412 patients treated with Interferon only versus standard of care, finding no significant difference on 28 day mortality [41].

\section{Immunomodulatory Therapies, Drugs and Targets}

The disease course of Covid-19 is thought to involve two phases: An initial phase of viral activity represented by the emergence of the classically described symptoms, followed by a second hyper-inflammatory phase a week or two later. It is this cytokine storm that is believed to be primarily responsible for the severe deterioration in those that develop Acute Respiratory Distress Syndrome (ARDS), which can result in a downward spiral towards multi-organ failure and death $[5,44]$. Three major strategies have been identified and trialled in the combat of this second phase. Firstly, use of the 'broad spectrum' immunomodulatory effects of well-established glucocorticoid drugs, such as prednisolone and dexamethasone. Secondly, there has been investigation into drugs directly targeting and inhibiting cytokines, including Granulocyte macrophage Colony Stimulating Factor (GM-CSF) and Interleukin 6 (IL-6). Thirdly, there have also been forays into treatment using plasma obtained from patients who have successfully recovered from Covid-19.

\section{Glucocorticosteroids}

Initial anecdotal evidence and small scale trials showed improved outcomes in Covid-19 patients treated with methylprednisolone [45], and in China there has been recommendation for the use of steroids in severe cases [46]. However, as the mechanism of action of glucocorticoids is incompletely understood, there were also widespread concerns over the use of immunosuppressant drugs in severe infective states [47]. However, with the hypothesis that these drugs could mitigate inflammation of the lung parenchyma and thereby lower the risk of progression to respiratory failure, the RECOVERY collaborative group trial got underway. This was an open label RCT with a total of 2104 hospitalised patients randomised to dexamethasone treatment in addition to the usual standard of care, the results from whom were compared to the usual care control group of 4321 patients. A statistically significant decrease in overall 28 day mortality rate was found in the dexamethasone treatment group (hazard ratio $0.83, p<0.001$ ), and this decrease in mortality was even more pronounced in the sub-analysis of patients that required me- 
chanical ventilation (hazard ratio $0.64, n=1007$ ), although no significant difference was found in those patients who did not require supplemental oxygen [48].

A pooled meta-analysis of seven RCTs also confirmed the benefit of administration of systemic corticosteroids, which was associated with lower 28 day all-cause mortality compared with usual care or placebo [49].

On the basis of these results, dexamethasone is now a recommendation for hospitalised patients that require supplemental oxygenation or ventilation, as was announced by the UK Chief Medical Officer in a Central Alert Message on $16^{\text {th }}$ June 2020 [50].

\section{The Cytokine storm: Treatment targets}

Immune cell-mediated lung damage has been theorised as a major contributor to the severity of Covid-19. Serum levels of IL-6 were found to be almost ten times higher in severe Covid-19 cases and associated with raised viral loads [51]. As this is only a statistical correlation, it is not clear whether the rise in IL-6 is a cause or effect of the severity of Covid-19 lung infection.

Two anti-IL-6 therapies, Tocilizumab and Sarilumab, have undergone recent trials in treating Covid-19. They are both humanised monoclonal antibodies and were already previously approved for treating autoimmune arthritides and for Chimeric Antigen Receptor T cell (CAR-T cell) therapy in cancer. An initial cohort study in China showed a reduction in fever and oxygen requirement in 21 patients with severe Covid-19 treated with Tocilizumab, although this result had no control group for comparison [52]. A retrospective case control cohort study in Italy in June 2020 compared 544 severe Covid-19 patients, of which 179 patients received Tocilizumab, and showed a significant risk reduction in the composite endpoint of death or mechanical ventilation (hazard ratio $0.60, p=0.003$ ) [53].

RCTs failed to reproduce such promise, however. Sarilumab's CORIMUNO trial was suspended due to futility, and the industry-sponsored COVACTA trial for Tocilizumab failed to show significant outcomes in any of its primary and secondary endpoints [54]. Indeed, there had already been reservations over the immune-suppressant effects of this class of drugs, as evidenced by their predisposition to secondary infections as seen in long term use with autoimmune conditions and cancer therapies. However, the wide inclusion criteria in the COVACTA trial resulted in a wide range of mild to severe Covid-19 cases in the study, which could confound the result. Multiple cohort studies and clinical trials have suggested that the early combination of Tocilizumab and steroids may confer additional benefit in severe Covid-19 cases [55,56]. Since dexamethasone has now become part of the standard of care, the UK RECOVERY group continues to trial Tocilizumab in severe Covid-19 cases, having already randomised over 850 patients (almost double those enrolled in COVACTA). This will help to shed further light on whether any benefits can be derived from Tocilizumab in combination with dexamethasone in Covid-19 infection [54].

\section{Convalescent Plasma transfusion}

Convalescent plasma, obtained from recently recovered patients, had been shown to improve clinical outcomes and reduce mortality in the previous SARS and MERS epidemics $[57,58]$. Initial case series from China seemed to reproduce this effect in Covid-19 patients, showing clinical improvement, clearing of viral load and reversal of ARDS in four out of five patients [59]. However, subsequent RCTs both in Wuhan, China for severe and life- threatening Covid-19 infection and in India for moderate infections failed to show improvement in mortality or TTR $[60,61]$. Interestingly, viral load clearance occurred much more quickly in the convalescent plasma treatment group versus standard care control group $(87.2 \%$ vs. $37.5 \%, p<0.001$ ) [61].

Despite these negative results, it is felt that identifying specific immunoglobulins/antibodies from convalescent plasma may hold part of the key to future therapies, including the development of the eventual vaccine [62]. Examples of monoclonal antibodies identified from convalescent plasma include LY-CoV555, which showed promising interim results in a phase 2 trial of 452 patients diagnosed with mild to moderate Covid-19. In patients receiving $2800 \mathrm{mg}$ of LY-CoV555, the viral load reduced by a factor of 3.4 vs. placebo $(n=107$, $p=0.02$ ). However, this will require further recruitment and analysis, as the significant difference seen at the $2800 \mathrm{mg}$ dose was lost with a $7000 \mathrm{mg}$ dose, which is counter-intuitive [63]. Despite this, on $9^{\text {th }}$ November 2020 the US Food and Drug Administration (FDA) authorised its use for mild to moderate cases of Covid-19 infection not requiring hospitalisation, with the new drug christened 'Bamlanivimab' [64].

Another promising example is REGN-COV2, a combination of two human monoclonal antibodies identified from convalescent plasma, which targets the spike glycoprotein of the SARS-CoV2 virus. In vivo study in Rhesus macaques and golden hamsters showed potential for both prophylaxis as well as treatment of Covid-19, with clearing of viral loads and amelioration of lung pathology [65]. The developers of this cocktail, Regeneron Pharmaceuticals, recently announced interim results from its ongoing phase $2 / 3$ trial of 275 recently diagnosed mild to moderate (non-hospitalised) Covid-19 patients randomised to either one of two doses of REGN-COV2 or placebo. Their results show highly significant reductions in viral load versus placebo with both high and low doses of REGNCOV2, although statistical significance was not achieved for the numerically lower median time to symptom alleviation [66]. This study is ongoing and has not been published fully for peer review; however due to promising findings the UK RECOVERY collaborative research group has commenced phase 3 trials to establish the benefits of REGN-COV2 in hospitalised Covid-19 patients [67].

\section{In Hospital Considerations: Supportive Mea- sures \& Therapies}

\section{Coagulopathy \& thromboembolism}

Following on from the theory of immune-mediated hyper-inflammatory state contributing to severe Covid-19 infec- 
tion, it has been widely suggested that hypercoagulability is at least partially responsible for ARDS in these cases. A combination of SARS-CoV2's affinity for pulmonary ACE-II receptors, diffuse interstitial and alveolar damage, the activation of macrophages and cytokines arriving from the pulmonary vascular endothelium, as well as profound hypoxia leading to increased plasma viscosity, is purported to predispose to coagulation in the pulmonary microvasculature in a similar manner to that seen in disseminated intravascular coagulation (DIC) in overwhelming sepsis [68]. Initial case reports emerged describing a DIC-like picture in severe Covid-19 infection, and there have also been case reports of systemic thromboembolism $[69,70]$. This hypercoagulable state is thought to cause the highest risk in the second week of the infection course, as illustrated by a significant rise in inflammatory markers ( $C$ reactive protein), D-dimer and Fibrinogen [71].

A retrospective analysis of 449 patients in a Wuhan hospital showed an apparent mortality benefit from the use of low molecular weight heparin (LMWH) for 7 days in the most severe cases of Covid-19 infection [72]. Further analysis of this data revealed that the mortality benefit was mostly seen in those patients receiving heparin who had a raised D-dimer [73].

It has already been established from previous meta-analysis of RCTs in ARDS patients that administration of LMWH can reduce the risk of mortality ( $48 \% 7$ day mortality risk reduction, $37 \% 28$ day mortality reduction) [74]. Therefore, although prospective RCTs are lacking for the use of anticoagulation in Covid-19, there has been a widespread recommendation for evaluating the thromboembolic risk of all hospitalised Covid-19 patients [68]. Algorithms for calculating the risk and determining the need for anticoagulation have been proposed by the European Society of Cardiology, who have suggested a heparin infusion for intensive care patients and a subcutaneous regimen of $1 \mathrm{mg} / \mathrm{kg}$ twice daily for non-high dependency patients [75].

\section{Oxygenation, ventilation and proning}

The most severe presentation of Covid-19 infection is with respiratory failure and ARDS, which is associated with a high risk of mortality [5]. Management of the airway of critically ill patients is challenging, and the increased risk of viral transmission to healthcare workers (HCWs) is now well documented during aerosol generating procedures (AGPS) [76]. Early on in the pandemic, some intensivists argued for early intubation and ventilation for Covid-19 patients even in cases with mild respiratory failure, suggesting that progressively vigorous inspiratory effort was the cause of lung injury [77]. However, with time it was recognised that despite meeting clinical criteria for ARDS, many Covid-19 patients had a mismatch between the degree of measured hypoxia and their lung compliance, with profound hypoxaemia in the presence of little respiratory distress [78]. Although mechanical ventilation is a life-saving intervention, it does not directly help the body to heal lung injury and in essence 'buys time' for the infected patient to develop an adequate immune response $[76,79]$. However, it would be extremely difficult to design a RCT in this severely unwell cohort of patients, not least of all due to the inability to blind intervention versus controls and the ethical unsoundness of such a venture.

Nonetheless, non-invasive ventilation treatment options are being compared in the UK RECOVERY (RECOVERY-RS) group trial, with 200 patients randomised so far as of $12^{\text {th }}$ October 2020 to help evaluate the effectiveness of Continuous Positive Airway Pressure (CPAP) and High Flow Nasal Oxygen (HFNO) versus standard care for Covid-19 patients with respiratory failure not requiring imminent intubation. This study is aiming to recruit 4000 patients into the 3 arms and is anticipated to complete in April 2021 [80].

Conscious proning has emerged as another possible therapeutic option in hospitalised patients not requiring ventilation. Prone positioning has been proven in RCTs and meta-analysis over the past two decades to be beneficial in improving oxygenation in mechanically ventilated ARDS patients, and rotational positioning has been adopted by intensive care units worldwide [81,82]. Multiple case series of conscious proning in moderate cases of hospitalised Covid-19 patients have now been published over the course of the pandemic, claiming to show improvement in hypoxia and potentially averting the need for intubation $[83,84]$. However, a rapid review of these studies concluded that the evidence base was hampered by a lack of any published RCTs, and that the results from ongoing RCTs will be needed to help decide if this is indeed a worthwhile intervention [85].

\section{Preventive Therapies and the Vaccine}

While vaccine development continued, the WHO recommended measures for the prevention of Covid-19 infection consisted of the strategies of social distancing, wearing face masks, frequent hand washing and isolation/quarantine measures for those infected or exposed to infected individuals [86]. In hospital settings, this extended to include guidelines for the use of personal protective equipment (PPE), with the use of the Filtering Face-Piece (FFP) class 2 and 3 masks conferring $95 \%$ and $99 \%$ fine particle filtration efficacy respectively [87].

December 2020 has finally seen the announcement and approval of a novel messenger RNA (mRNA) based vaccine purported to have $95 \%$ efficacy in preventing Covid-19 infection, developed by the pharmaceutical companies Pfizer and BioNTech in collaboration. Despite no Phase III trial results being published in peer- reviewed journals as of $10^{\text {th }}$ Dec 2020, the UK Medicines and Health Regulatory Agency, an independent body, approved this vaccine on $2^{\text {nd }}$ Dec, based on trial results made available to them prior to publication. This was unprecedented as the UK would normally await approval by the European Medicines Agency (EMA) prior to authorising the distribution of a new drug. The UK government made legislative changes in October 2020 allowing emergency use authorisation for such a scenario. The MHRA reported no safety concerns and were satisfied with the efficacy results [88]. The UK National Health Service began offering the vaccine to adults aged over 80 years of age on $8^{\text {th }}$ December 2020 [88]. The Moderna pharmaceuticals vaccine is also mRNA-based and is yet to have results published or achieve approval, de- 
spite reportedly similar positive interim results.

The AstraZeneca/Oxford ChAdOx1 nCoV-19 vaccine is a replication-deficient adenovirus modified to express the SARS-Cov-2 structural surface glycoprotein. Interim results from the first 11,636 trial participants have just been published, showing up to $90 \%$ efficacy $(p=0.01)$ depending on the dose regimen, with no significant safety concerns [89]. The trial is ongoing with a total of 23,848 participants enrolled by November 2020, and the scientific community awaits the full results with interest; as a 'traditional' vaccine it is likely to be the most cost- effective and widely used should it gain approval.

\section{Conclusion}

It is now clear that the treatment of Covid-19 requires a multi-faceted approach, considering both the severity of infection, the two phases of its clinical syndrome and the mech- anisms of organ injury. The only drug class that has shown proven benefit so far is ironically one of the oldest; glucocorticoids, in particular Dexamethasone, have humbled the medical profession yet again. And an even older medicineheparin- is also rapidly becoming considered an essential part of the treatment of severe Covid-19. However, as we are now deep into the so-called 'second wave', much vital research is ongoing. There is promise in the initial results seen from trials of human monoclonal antibodies conferring passive immunity, but it remains to be seen if these will actually prove to be the much-needed remedy or in the end fall by the wayside along with so many of the other trialled treatments. Nonetheless, with the approval of multiple vaccines around the corner, a glimmer of hope has emerged that we are finally on the cusp of conquering this disease (Table 1).

\section{Conflicts of Interest}

None.

Table 1: Summary table of trialled therapies for Covid-19.

\begin{tabular}{|c|c|c|}
\hline Drug/treatment & Class/Mechanism of action & Results of Covid-19 trials \\
\hline \multicolumn{3}{|c|}{ Drugs with antiviral activity } \\
\hline $\begin{array}{l}\text { Chloroquine/ } \\
\text { Hydroxychloroquine }\end{array}$ & $\begin{array}{l}\text {-Quinolone class (antimalarial) } \\
\text {-Alkalinisation of endosomes \& inhibition of ACE-II } \\
\text { glycosylation, preventing virus binding \& cell entry }\end{array}$ & $\begin{array}{l}\text { RECOVERY trial- no significant difference in mortality } \\
\text { or TTR. Confirmed with multiple meta-analyses Aug } \\
2020[21,22]\end{array}$ \\
\hline Azithromycin & $\begin{array}{l}\text {-Macrolide bacteriostatic antibiotic } \\
\text {-Inhibits mRNA translation on bacterial ribosome; } \\
\text { theorised to have similar effect on virus }\end{array}$ & $\begin{array}{l}\text { Increased risk of adverse effects and mortality in } \\
\text { combination with hydroxychloroquine (meta-analysis } \\
\text { of } 7 \text { studies) RR1.27, } 95 \% \mathrm{Cl} 1.04-1.54 \text { [22] }\end{array}$ \\
\hline Ivermectin & $\begin{array}{l}\text {-Antiparasitic macrocyclic lactone } \\
\text {-Cellular hyperpolarisation via binding glutamate- } \\
\text { gated chloride channel receptor (GluCIR) causing } \\
\text { cell paralysis/death }\end{array}$ & $\begin{array}{l}\text { In Vitro effectiveness against SARS-CoV-2; cohort study } \\
\text { meta-analysis suggests mortality and TTR benefits } \\
{[27,28] \text {. }} \\
\text { RCTs awaited. }\end{array}$ \\
\hline Remdesivir & $\begin{array}{l}\text {-Prodrug- active metabolite ATP analogue } \\
\text {-Inhibits RNA-dependent RNA polymerase, } \\
\text { preventing viral replication }\end{array}$ & $\begin{array}{l}\text { 31\% Improvement in TTR, no effect on mortality in } \\
\text { ACTT trial }(p<0.001)[35] \text {. } \\
\text { SIMPLE trial showed no additional safety concerns (not } \\
\text { placebo controlled) [36]. } \\
\text { Approved by US FDA Oct } 2020 .\end{array}$ \\
\hline Favipiravir & $\begin{array}{l}\text {-Prodrug- active metabolite inhibits RNA- } \\
\text { dependent RNA polymerase } \\
\text {-Prevents viral replication }\end{array}$ & $\begin{array}{l}\text { WHO SOLIDARITY Study: No significant benefit in } \\
\text { mortality, TTR or illness severity [42]. }\end{array}$ \\
\hline Lopinavir/ Ritonavir & $\begin{array}{l}\text {-Anti-retroviral drug combination (HIV protease } \\
\text { inhibitors) } \\
\text {-Bind viral protease, preventing antigen } \\
\text { production }\end{array}$ & $\begin{array}{l}\text { Largest RCT ( } n=199 \text { ) showed no benefit in TTR, } \\
\text { mortality or viral load clearance [40]. } \\
\text { WHO SOLIDARITY Study: No significant benefit in } \\
\text { mortality, TTR or illness severity [42]. }\end{array}$ \\
\hline \multicolumn{3}{|c|}{ Drugs with immunomodulatory functions } \\
\hline Interferon Beta-1a & $\begin{array}{l}\text {-Recombinant human interferon (cytokine); } \\
\text { licensed for Multiple sclerosis } \\
\text {-Reduces inflammation, inhibits production of T } \\
\text { helper cells }\end{array}$ & $\begin{array}{l}\text { WHO SOLIDARITY Study: No significant benefit in } \\
\text { mortality, TTR or illness severity [42]. } \\
\text { RCTs ongoing trialling inhaled regimen. }\end{array}$ \\
\hline Glucocorticoids & $\begin{array}{l}\text {-Anti-inflammatory, pleotropic effects and usage } \\
\text {-Bind glucocorticoid receptors, stimulating anti- } \\
\text { inflammatory protein production }\end{array}$ & $\begin{array}{l}\text { RECOVERY trial ( } n=2104 \text { vs. } 4321 \text { usual care): } \\
\text { Decreased 28-day mortality HR0.83, } p<0.001 \text { [49]. } \\
\text { Confirmed with Pooled meta-analysis of } 7 \text { RCTs [50]. }\end{array}$ \\
\hline
\end{tabular}


Citation: Rahim SMZ, Connolly DL, Rajasekaran AB, et al. (2020) Covid-19 Treatment: A Narrative Review of the Research and Evidence Thus Far. Sch J Emerg Med Crit Care 4(1):96-105

\begin{tabular}{|c|c|c|}
\hline Tocilizumab & $\begin{array}{l}\text {-Humanised monoclonal antibody (anti-IL6 } \\
\text { cytokine receptor); licensed for Rheumatoid } \\
\text { arthritis } \\
\text {-Suppression of pro-inflammatory interleukin } 6\end{array}$ & $\begin{array}{l}\text { COVACTA trial- no significant difference in mortality, } \\
\text { TTR [55]. } \\
\text { Cohort studies suggest benefit in combination with } \\
\text { steroids [56,57]. } \\
\text { RECOVERY trial ongoing. }\end{array}$ \\
\hline Sarilumab & $\begin{array}{l}\text { - Humanised monoclonal antibody (anti-IL6 } \\
\text { cytokine receptor); licensed for Rheumatoid } \\
\text { arthritis } \\
\text {-Suppression of pro-inflammatory interleukin } 6\end{array}$ & $\begin{array}{l}\text { CORIMUNO trial halted in Sep } 2020 \text { due to lack of } \\
\text { efficacy [55]. }\end{array}$ \\
\hline Convalescent plasma & $\begin{array}{l}\text {-Antibodies from the plasma of Covid-19- } \\
\text { recovered individuals } \\
\text {-Likely to confer passive immunity only }\end{array}$ & $\begin{array}{l}\text { Two RCTs (China, India) failed to show mortality or TTR } \\
\text { benefit despite significantly quicker viral load clearance } \\
{[61,62] \text {. }}\end{array}$ \\
\hline Bamlanivimab & $\begin{array}{l}\text {-Monoclonal antibody identified from } \\
\text { convalescent plasma } \\
\text {-Likely to confer passive immunity only }\end{array}$ & $\begin{array}{l}\text { Interim RCT results show significant viral load } \\
\text { reduction with lower dose ( } 2800 \mathrm{mg} \text { ) not seen with } \\
7000 \mathrm{mg} \text { dose [64]. } \\
\text { US FDA approval in Nov } 2020 \text { for non-hospitalised } \\
\text { Covid-19 cases (prior to full publication of trial results) } \\
\text { [65]. }\end{array}$ \\
\hline REGN-COV2 & $\begin{array}{l}\text {-Combination of two monoclonal antibodies } \\
\text { identified from convalescent plasma } \\
\text { - Likely to confer passive immunity only }\end{array}$ & $\begin{array}{l}\text { Interim RCT results show significant viral load } \\
\text { reduction but no difference in TTR in non- hospitalised } \\
\text { Covid-19 patients [67]. } \\
\text { RECOVERY trial ongoing for hospitalised patients [68]. }\end{array}$ \\
\hline \multicolumn{3}{|l|}{ Supportive measures } \\
\hline Anticoagulation & $\begin{array}{l}\text {-Heparin and derivatives } \\
\text {-To treat hypercoagulable pro-inflammatory state }\end{array}$ & $\begin{array}{l}\text { Evidence base from historical (pre-Covid-19 era) meta- } \\
\text { analysis of RCTs in ARDS patients showing } 48 \% \text { 7-day } \\
\text { and } 37 \% \text { 28-day reduction in mortality [75]. } \\
\text { Retrospective analyses of Covid-19 patients in } \\
\text { China show apparent mortality benefit of } 7 \text { days } \\
\text { anticoagulation with LMWH }[73,74] .\end{array}$ \\
\hline $\begin{array}{l}\text { Non-invasive ventilation, } \\
\text { conscious proning }\end{array}$ & $\begin{array}{l}\text {-Positive/bi-level pressure mask ventilation to aid } \\
\text { oxygenation in hypoxic states } \\
\text {-Proning (alternating supine and prone positioning } \\
\text { during ventilation to allow aeration of entire lung) }\end{array}$ & $\begin{array}{l}\text { RECOVERY-RS trial ongoing to evaluate HFNO vs. CPAP } \\
\text { [81]. } \\
\text { Case series show conscious proning in moderate cases } \\
\text { of Covid-19 shown improves hypoxia and decreases } \\
\text { risk of progression to intubation }[84,85] \text {. }\end{array}$ \\
\hline Invasive ventilation & $\begin{array}{l}\text {-Mechanical ventilation after endotracheal } \\
\text { intubation used in cases of severe hypoxia and } \\
\text { poor respiratory reserve }\end{array}$ & $\begin{array}{l}\text { Mechanical ventilation known to be lifesaving in ARDS. } \\
\text { Difficult to ethically design RCT. }\end{array}$ \\
\hline \multicolumn{3}{|l|}{ The Vaccines } \\
\hline Pfizer/BioNTech & $\begin{array}{l}\text {-messenger RNA coding for SARS-CoV-2 surface } \\
\text { spike glycoprotein } \\
\text {-Stimulates production of antibodies to the } \\
\text { resulting antigen without viral infection }\end{array}$ & $\begin{array}{l}\text { Approved by UK MHRA and US FDA in Dec } 2020 \text { on } \\
\text { basis of results made available prior to peer-reviewed } \\
\text { publication [89]. }\end{array}$ \\
\hline Moderna & $\begin{array}{l}\text {-messenger RNA coding for SARS-CoV-2 surface } \\
\text { spike glycoprotein } \\
\text {-Stimulates production of antibodies to the } \\
\text { resulting antigen without viral infection }\end{array}$ & $\begin{array}{l}\text { Awaiting publication of full results; interim results } \\
\text { announced claiming } 95 \% \text { efficacy }\end{array}$ \\
\hline $\begin{array}{l}\text { Oxford/AstraZeneca } \\
\text { (ChAdOx1 nCOV-19) }\end{array}$ & $\begin{array}{l}\text {-Replication deficient adenovirus modified to } \\
\text { express SARS-CoV-2 surface spike glycoprotein }\end{array}$ & $\begin{array}{l}\text { Interim results of } 11,636 \text { trial participants showing up } \\
\text { to } 90 \% \text { efficacy at low dose regimen with no significant } \\
\text { safety concerns [90]. } \\
\text { Full results awaited. }\end{array}$ \\
\hline
\end{tabular}




\section{References}

1. Coronaviridae Study Group of the International Committee on Taxonomy of Viruses (2020) The species severe acute respiratory syndrome-related Coronavirus: Classifying 2019-nCoV and naming it SARS-CoV-2. Nat Microbiol 5: 536-544.

2. (2020) WHO Covid-19 dashboard.

3. Wu SL, Mertens AN, Crider YS, et al. (2020) Substantial underestimation of SARS-CoV-2 infection in the United States. Nat Commun 11: 4507.

4. Shah A, Kashyap R, Tosh P, et al. (2020) Guide to understanding the 2019 novel coronavirus. Mayo Clin Proc 95: 646-652.

5. Huang C, Wang Y, Li X (2020) Clinical features of patients infected with 2019 novel coronavirus in Wuhan, China. Lancet 395 497-506.

6. Savarino A, Boelaert JR, Cassone A, et al. (2003) Effects of chloroquine on viral infections: An old drug against today's diseases? Lancet Infect Dis 3: 722-727.

7. Pani A, Lauriola M, Romandini A, et al. (2020) Macrolides and viral infections: Focus on azithromycin in COVID-19 pathology. Int J Antimicrob Agents 56: 106053.

8. Keyaerts E, Li S, Vijgen L, et al. (2009) Antiviral activity of chloroquine against human Coronavirus OC43 infection in newborn mice. Antimicrob Agents Chemother 53: 3416-3421.

9. Paton $\mathrm{NI}$, Lee L, Xu Y, et al. (2011) Chloroquine for influenza prevention: A randomised, double-blind, placebo controlled trial. Lancet Infect Dis 11: 677-683.

10. Wang M, Cao R, Zhang L, et al. (2020) Remdesivir and chloroquine effectively inhibit the recently emerged novel coronavirus (2019-nCoV) in vitro. Cell Res 30: 269-271.

11. Gao J, Hu S (2020) Update on use of chloroquine/hydroxychloroquine to treat coronavirus disease 2019 (COVID-19). Biosci Trends 14: 156-158.

12. Gautret P, Lagier JC, Parola P, et al. (2020) Clinical and microbiological effect of a combination of hydroxychloroquine and azithromycin in 80 COVID-19 patients with at least a six-day follow up: A pilot observational study. Travel Med Infect Dis 34: 101663.

13. Million M, Lagier JC, Gautret P, et al. (2020) Early treatment of COVID-19 patients with hydroxychloroquine and azithromycin: A retrospective analysis of 1061 cases in Marseille, France. Travel Med Infect Dis 35: 101738.

14. Rosenberg ES, Dufort EM, Udo T, et al. (2020) Association of treatment with hydroxychloroquine or azithromycin with in-hospital mortality in patients with COVID-19 in New York State. JAMA 323: 2493-2502.

15. Tang W, Cao Z, Han M, et al. (2020) Hydroxychloroquine in patients with mainly mild to moderate coronavirus disease 2019: Open label, randomised controlled trial. BMJ 369: m1849.

16. Boulware DR, Pullen MF, Bangdiwala AS, et al. (2020) A randomized trial of hydroxychloroquine as postexposure prophylaxis for Covid-19. N Engl J Med 383: 517-525.

17. Cavalcanti AB, Zampieri FG, Rosa RG, et al. (2020) Hydroxychloroquine with or without azithromycin in mild-to-moderate Covid-19. N Engl J Med 383: 2041-2052.

18. RECOVERY Collaborative Group, Horby $P$, Mafham $M$, et al. (2020) Effect of hydroxychloroquine in hospitalized patients with
Covid-19. N Engl J Med 383: 2030-2040.

19. Chatre C, Roubille F, Vernhet H, et al. (2018) Cardiac complications attributed to chloroquine and hydroxychloroquine: A systematic review of the literature. Drug Saf 41: 919-931.

20. Jankelson L, Karam G, Becker ML, et al. (2020) QT prolongation, torsades de pointes, and sudden death with short courses of chloroquine or hydroxychloroquine as used in COVID-19: A systematic review. Heart Rhythm 17: 1472-1479.

21. Chen C, Pan K, Wu B, et al. (2020) Safety of hydroxychloroquine in COVID-19 and other diseases: A systematic review and meta-analysis of 53 randomized trials. Eur J Clin Pharmacol 11: 1-12.

22. Fiolet T, Guihur A, Rebeaud ME, et al. (2020) Effect of hydroxychloroquine with or without azithromycin on the mortality of coronavirus disease 2019 (COVID-19) patients: A systematic review and meta-analysis. Clin Microbiol Infect.

23. Giudicessi JR, Noseworthy PA, Friedman PA, et al. (2020) Urgent guidance for navigating and circumventing the QTc-prolonging and torsadogenic potential of possible pharmacotherapies for coronavirus disease 19 (COVID-19). Mayo Clin Proc 95: 12131221.

24. Crump A, Omura S (2011) Ivermectin, 'wonderdrug' from Japan: The human use perspective. Proc Jpn Acad Ser B Phys Biol Sci 87: $13-28$.

25. Sharun K, Dhama K, Patel SK, et al. (2020) Ivermectin, a new candidate therapeutic against SARS-CoV-2/COVID-19. Ann Clin Microbiol Antimicrob 19: 23.

26. Caly L, Druce JD, Catton MG, et al. (2020) The FDA-approved drug ivermectin inhibits the replication of SARS- CoV-2 in vitro. Antiviral Res 178: 104787.

27. Padhy BM, Mohanty RR, Das S, et al. (2020) Therapeutic potential of ivermectin as add on treatment in COVID 19: A systematic review and meta-analysis. J Pharm Pharm Sci 23: 462-469.

28. Rajter JC, Sherman MS, Fatteh N, et al. (2020) Use of ivermectin is associated with lower mortality in hospitalized patients with coronavirus disease 2019: The ICON Study. Chest.

29. Sheahan TP, Sims AC, Graham RL, et al. (2017) Broad-spectrum antiviral GS-5734 inhibits both epidemic and zoonotic coronaviruses. Sci Transl Med 9: eaal3653.

30. (2020) Press release: Summary on compassionate use Remdesivir Gilead.

31. Mulangu S, Dodd LE, Davey RT Jr, et al. (2019) A randomized, controlled trial of Ebola virus disease therapeutics. N Engl J Med 381: 2293-2303.

32. Williamson BN, Feldmann F, Schwarz B, et al. (2020) Clinical benefit of Remdesivir in rhesus macaques infected with SARS-CoV-2. bioRxiv.

33. Wang $Y$, Zhang D, Du G, et al. (2020) Remdesivir in adults with severe COVID-19: A randomised, double-blind, placebo-controlled, multicentre trial. Lancet 395: P1569-P1578.

34. Beigel JH, Tomashek KM, Dodd LE, et al. (2020) Remdesivir for the treatment of Covid-19 - final report. N Engl J Med 383: 18131826.

35. (2020) Press release: Gilead announces results from phase 3 trial of investigational antiviral remdesivir in patients with severe COVID-19. 
Citation: Rahim SMZ, Connolly DL, Rajasekaran AB, et al. (2020) Covid-19 Treatment: A Narrative Review of the Research and Evidence Thus Far. Sch J Emerg Med Crit Care 4(1):96-105

36. (2020) Press release: FDA's approval of Veklury (remdesivir) for the treatment of COVID-19 - The Science of safety and effectiveness.

37. Koba H, Yoneda T, Kaneda T, et al. (2020) Severe coronavirus disease 2019 (COVID-19) pneumonia patients treated successfully with a combination of lopinavir/ritonavir plus favipiravir: Case series. Clin Case Rep.

38. Chu CM, Cheng VC, Hung IF, et al. (2004) Role of lopinavir/ritonavir in the treatment of SARS: Initial virological and clinical findings. Thorax 59: 252-256.

39. Cao B, Wang Y, Wen D, et al. (2020) A trial of lopinavir-ritonavir in adults hospitalized with severe Covid-19. N Engl J Med 382: 1787-1799.

40. RECOVERY Collaborative Group (2020) Lopinavir-ritonavir in patients admitted to hospital with COVID-19 (RECOVERY): A randomised, controlled, open-label, platform trial. Lancet 396: P1345-P1352.

41. Pan H, Peto R, Abdool Karim Q, et al. (2020) WHO Solidarity trial consortium. Repurposed antiviral drugs for COVID-19 -interim WHO SOLIDARITY trial results. medRxiv.

42. (2020) Press release: Gilead statement on Solidarity trial.

43. Mantlo E, Bukreyeva N, Maruyama J, et al. (2020) Potent antivira activities of type I interferons to SARS-CoV-2 infection. bioRxiv.

44. Zhou Y, Fu B, Zheng X, et al. (2020) Aberrant pathogenic GM-CSF+ $T$ cells and inflammatory $C D 14+C D 16+$ monocytes in severe pulmonary syndrome patients of a new coronavirus. bioRxiv.

45. Corral L, Bahamonde A, Arnaiz de las RF, et al. (2020) GLUCOCOVID: A controlled trial of methylprednisolone in adults hospitalized with COVID-19 pneumonia. medRxiv.

46. Zhao JP, Hu Y, Du RH, et al. (2020) Expert consensus on the use of corticosteroid in patients with 2019-nCoV pneumonia. Zhonghua Jie He He Hu Xi Za Zhi 43: 183-184.

47. Russell CD, Millar JE, Baillie JK (2020) Clinical evidence does not support corticosteroid treatment for 2019- nCoV lung injury. Lancet 395: 473-475.

48. RECOVERY Collaborative Group, Horby P, Lim WS, et al. (2020) Dexamethasone in hospitalized patients with Covid-19 - Preliminary report. N Engl J Med.

49. WHO Rapid Evidence Appraisal for COVID-19 Therapies (REACT) Working Group, Sterne JAC, Murthy S, Diaz JV, et al. (2020) Association between administration of systemic corticosteroids and mortality among critically III patients with COVID-19: A meta-analysis. JAMA 324: 1330-1341.

50. MHRA Central alerting system (2020) Dexamethasone in the treatment of COVID-19: Implementation and management of supply for treatment in hospitals.

51. Chen X, Zhao B, Qu Y, et al. (2020) Detectable serum SARS-CoV-2 viral load (RNAaemia) is closely associated with drastically elevated interleukin 6 (IL-6) level in critically ill COVID-19 patients. Clin Infect Dis.

52. Xu X, Han M, Li T, et al. (2020) Effective treatment of severe COVID-19 patients with tocilizumab. Proc Natl Acad Sci U S A 117: 10970-10975.

53. Guaraldi G, Meschiari M, Cozzi LA, et al. (2020) Tocilizumab in patients with severe COVID-19: A retrospective cohort study. Lancet 2: E474-E484.
54. Furlow B (2020) COVACTA trial raises questions about tocilizumab's benefit in COVID-19. Lancet Rheumatol 2: e592.

55. Ruiz AB, Sancho LA, Torres F, et al. (2020) Combination of Tocilizumab and steroids to improve mortality in patients with severe COVID-19 Infection: A Spanish, multicenter, cohort study. Infect Dis Ther.

56. Mikulska M, Nicolini LA, Signori A, et al. (2020) Tocilizumab and steroid treatment in patients with COVID-19 pneumonia. PLoS One 15: e0237831.

57. Lai ST (2005) Treatment of severe acute respiratory syndrome. Eur J Clin Microbiol Infect Dis 24: 583-591.

58. Arabi Y, Balkhy H, Hajeer AH (2015) Feasibility, safety, clinical, and laboratory effects of convalescent plasma therapy for patients with Middle East respiratory syndrome coronavirus infection: A study protocol. Springerplus 4: 709.

59. Shen C, Wang Z, Zhao F, et al. (2020) Treatment of 5 critically ill patients with COVID-19 with convalescent plasma. JAMA 323: 1582-1589.

60. Li L, Zhang W, Hu Y, et al. (2020) Effect of convalescent plasma therapy on time to clinical improvement in patients with severe and life-threatening COVID-19: A randomized clinical trial. JAMA 324: 460-470.

61. Agarwal A, Mukherjee A, Kumar G, et al. (2020) Convalescent plasma in the management of moderate covid-19 in adults in India: Open label phase II multicentre randomised controlled trial (PLACID Trial). BMJ 371: m3939.

62. Robbiani DF, Gaebler C, Muecksch F, et al. (2020) Convergent antibody responses to SARS-CoV-2 in convalescent individuals. Nature 584: 437-442.

63. Chen P, Nirula A, Heller B, et al. (2020) SARS-CoV-2 neutralizing antibody LY- CoV555 in outpatients with Covid-19. N Engl J Med.

64. Mahase E (2020) Covid-19: FDA authorises neutralising antibody bamlanivimab for non-admitted patients. BMJ 371: $\mathrm{m} 4362$.

65. Baum A, Ajithdoss D, Copin R, et al. (2020) REGN-COV2 antibodies prevent and treat SARS-CoV-2 infection in rhesus macaques and hamsters. Science 370: 1110-1115.

66. (2020) Press release: Regeneron's REGN-COV2 antibody cocktail reduced viral levels and improved symptoms in non-hospitalized COVID-19 patients.

67. (2020) Press Release: RECOVERY COVID-19 phase 3 trial to evaluate Regeneron's REGN-COV2 investigational antibody cocktail in the UK.

68. Rico MJS, Rosas D, Ahmadian TA, et al. (2020) The role of anticoagulation in COVID-19-induced hypercoagulability. Curr Cardiol Rep 22: 53.

69. Mahajan P, Dass B, Radhakrishnan N, et al. (2020) COVID-19-associated systemic thromboembolism: A case report and review of the literature. Cardiorenal Med 22: 1-8.

70. Sang CJ3rd, Heindl B, Von Mering G, et al. (2020) Massive pulmonary embolism in a COVID-19 patient: A case report. Eur Heart J Case Rep 4: 1-5.

71. Lin L, Lu L, Cao W, et al. (2020) Hypothesis for potential pathogenesis of SARS-CoV-2 infection-a review of immune changes in patients with viral pneumonia. Emerg Microbes Infect 9: 727732.

72. Tang N, Bai $H$, Chen $X$, et al. (2020) Anticoagulant treatment is 
associated with decreased mortality in severe coronavirus disease 2019 patients with coagulopathy. J Thromb Haemost 18: 1094-1099.

73. Yin S, Huang M, Li D, et al. (2020) Difference of coagulation features between severe pneumonia induced by SARS-CoV2 and non-SARS-CoV2. J Thromb Thrombolysis 3: 1-4.

74. Li J, Li Y, Yang B, et al. (2018) Low-molecular-weight heparin treatment for acute lung injury/acute respiratory distress syndrome: A meta-analysis of randomized controlled trials. Int J Clin Exp Med 11: 414-422.

75. Atallah B, Mallah SI, AlMahmeed W (2020) Anticoagulation in COVID-19. European Heart Journal - Cardiovascular Pharmacotherapy 6: 260-261.

76. Cook TM, El-Boghdadly K, McGuire B, et al. (2020) Consensus guidelines for managing the airway in patients with COVID-19: Guidelines from the difficult airway society, the association of anaesthetists the intensive care society, the faculty of intensive care medicine and the royal college of anaesthetists. Anaesthesia 75: 785-799.

77. Marini JJ, Gattinoni L (2020) Management of COVID-19 respiratory distress. JAMA 323: 2329-2330.

78. Gattinoni L, Coppola S, Cressoni M, et al. (2020) COVID-19 does not lead to a "Typical" acute respiratory distress syndrome. Am J Respir Crit Care Med 201: 1299-1300.

79. Tobin MJ (2020) Basing respiratory management of COVID-19 on physiological principles. Am J Respir CritCare Med 201: 13191320.

80. Perkins GD, Couper K, Connolly B, et al. (2020) RECOVERY- respiratory support: Respiratory strategies for patients with suspected or proven COVID-19 respiratory failure; continuous positive airway pressure, high- flow nasal oxygen, and standard care: A structured summary of a study protocol for a randomised controlled trial. Trials 21: 687.

81. Guérin C, Reignier J, Richard JC, et al. (2013) PROSEVA study group. Prone positioning in severe acute respiratory distress syndrome. N Engl J Med 368: 2159-2168.

82. Sud S, Friedrich JO, Taccone P, et al. (2010) Prone ventilation reduces mortality in patients with acute respiratory failure and severe hypoxemia: Systematic review and meta-analysis. Intensive Care Med 36: 585-599.

83. Caputo ND, Strayer RJ, Levitan R (2020) Early self-proning in awake, non-intubated patients in the emergency department: A single ed's experience during the COVID-19 pandemic. Acad Emerg Med 27: 375-378.

84. Paul V, Patel S, Royse M, et al. (2020) Proning in non-intubated (PINI) in times of COVID-19: Case series and a review. J Intensive Care Med 35: 818-824.

85. Weatherald J, Solverson K, Zuege DJ, et al. (2020) Awake prone positioning for COVID-19 hypoxemic respiratory failure: A rapid review. J Crit Care 61: 63-70.

86. World Health Organizaion (2020) Coronavirus disease (COVID-19) advice for the public.

87. World Health Organization (2020) Rational use of personal protective equipment for coronavirus disease (COVID-19) and considerations during severe shortages: Interim guidance, 6 April 2020.

88. Mahase E (2020) Vaccinating the UK: How the covid vaccine was approved, and other questions answered. BMJ 371: $\mathrm{m} 4759$.

89. Voysey M, Clemens SAC, Madhi SA, et al. (2020) Safety and efficacy of the ChAdOx1 nCoV-19 vaccine (AZD1222) against SARSCoV-2: An interim analysis of four randomised controlled trials in Brazil, South Africa, and the UK. Lancet.

DOI: $10.36959 / 592 / 390$

Copyright: (C) 2020 Rahim SMZ, et al. This is an open-access article distributed under the terms of the Creative Commons Attribution License, which permits unrestricted use, distribution, and reproduction in any medium, provided the original author and source are credited. 